\title{
A Preliminary Study on Accident Analysis of Portable Timber Sawmills Used in Mazamba Forest Plantation in Northern Malawi
}

\author{
Jameson T. T. Mzungu and Elisha S. Ngulube \\ Department of Forestry and Environmental Management, Faculty of Environmental Sciences, Mzuzu University, \\ Mzuzu 105203, Malawi \\ Correspondence should be addressed to Elisha S. Ngulube; esn12003@yahoo.co.uk
}

Received 7 April 2020; Revised 25 August 2020; Accepted 27 August 2020; Published 25 September 2020

Academic Editor: Anna Źróbek-Sokolnik

Copyright ( $) 2020$ Jameson T. T. Mzungu and Elisha S. Ngulube. This is an open access article distributed under the Creative Commons Attribution License, which permits unrestricted use, distribution, and reproduction in any medium, provided the original work is properly cited.

\begin{abstract}
This study investigated the main causes of accidents, levels of injuries, and mitigation measures to wood processing accidents. Structured interviews were conducted on 45 respondents drawn from various portable sawmills. The Chi square test showed that there were highly significant differences on frequency distribution of causes of sawmill accidents. However, a principal component analysis revealed that accidents were mainly caused by inappropriate equipment setup or operation and harsh weather conditions. Secondly, results showed that the frequency distribution of responses on levels of accidents was highly significantly different among the respondents. Near-misses accounted for most of responses (55.6\%). This is because nearmisses are precursors to secondary accidents. Furthermore, the results showed highly significant differences on the frequency distribution of various mitigation measures available. Use of personal protective equipment and provision of special training were highly appraised. Forest workers need occupation safety and health and ergonomic knowledge before engaging in wood processing.
\end{abstract}

\section{Introduction}

Wood processing industries are regarded as high health and safety risk occupations in many parts of the world [1-3]. Over 2 million people in the world are believed to be dying each year as a result of forest-related accidents [4]. Most of the accidents occur during tree felling, manual timber extraction (log rolling), and portable sawmilling operations. Heinrich [5] postulated that, for every 300 near-misses, there are 29 injuries with a probability that one of those injuries being fatal. Naturally, accidents are unplanned, unforeseen, and unwanted events of a random character [6-8] in the forest workplace.

Forests are inherently dangerous work environments [9-11] owing to their locations and nature of the operations that are involved. Forest operations usually take place under adverse working conditions such as on steep slopes, remote areas, and harsh weather conditions. Furthermore, forest workers are typically exposed to sharp, heavy, and highspeed machine moving parts as they execute their operations. The tasks are generally physical and mentally demanding leading to body fatigue and musculoskeletal pains $[12,13]$. Critical operational judgments ought to be made timeously and judiciously in order to enable translation of actions into sound safety responses in workplaces [14]. A study conducted in New Zealand reported that the forest sector registered the highest injury rates of which $30 \%$ of logging injuries occur during the felling task [15]. The Centre for Human Factors and Ergonomics [16] reported that sawmills account for at least $50 \%$ of all the injury claims in the wood processing industries followed by the pulp and ply-mills. In Italy, however, the plywood industry had been reported to be at least twice more accident prone than other sectoral manufacturing industries [17]. On the other hand, $25 \%$ of accidents in developing countries are caused by tree hang-ups [18]. In Tanzania, Silayo et al. [19] reported that at least $50 \%$ of the timber harvesting crews get involved in accidents in one way or another in the course of executing their operations. It is clear, therefore, from these reports that 
both the forest and wood processing industries have high accident risks.

In northern Malawi, wood processing is mostly done by small-scale but many sawmills. Operation of these mills is mostly dominated by a work force that does not have formal training. Workers pass on skills to one another right on job. Unfortunately, these operational skills nebulously carry occupational safety skills. Poor operational skills include, but not limited to, poor setting up of machines on the ground, playing unsafe acts, and working in unsafe conditions [20]. Sawmills ought to be set on well-levelled grounds or on solid concrete foundations to avoid machine vibrations or even falling off. Unsafe acts constitute unacceptable behaviours of operators (such as horseplay, repairing machines while in motion, and working while drunk) at work. This is a cause for concern as productive youths continually get involved in workplace accidents in Viphya (Mr. S. Nyandeni, 2018, Forester, Viphya Forest Plantations, Malawi, pers. comm.).

Occupational health and safety has a significant effect on the social and economic thrust in the forest sector and society $[21,22]$. Accidents have the potential to reduce productivity [19] and degrade corporate image of the forest sector [23] owing to the fact that occupational safety and health is a human right for every person. Papadopoulos et al. [24] stressed that occupational safety management and the associated decisions must enable protection of the workforce at all costs. This withstanding, such interventions become difficult to execute in the absence of comprehensive accident databases in workplaces $[25,26]$. Anecdotal evidence shows that many forest workers are highly involved in occupational accidents on the Viphya forest plantation sawmills. Unfortunately, such information has not been investigated to provide insights that can inform strategic and focused decisions on forest accident prevention research. Therefore, the objectives of this study were to determine the main causes of accidents, assess the levels of injuries, and determine the mitigation measures of accidents in portable saw milling operations in northern Malawi.

\section{Methodology}

2.1. Description of the Study Site. The study was conducted at Mazamba forest station on the Viphya forest plantations between 2016 and 2018. Mazamba forest is located in Nkhata Bay district in northern Malawi. It shares its borders with Champhoyo forest to the south, Nthungwa forest to the west, and Lusangazi forest to the north (Figure 1). The forest covers 6,450 hectares composed of tropical exotic trees species such as Pinus patula, P. oorcapa, P. taeda, and Eucalyptus grandis. Generally, Mazamba receives $>1000 \mathrm{~mm} \cdot \mathrm{yr}^{-1}$ on average of rainfall in summer but it becomes cooler and misty in winter months. Mazamba was purposively selected because it was the only active smallscale timber harvesting and wood processing site on the Viphya forest plantations during the time of the study. During the time of study, forest and wood processing accidents occurred more frequently at Mazamba. There were four active small industrial sites where portable sawmilling operations were taking place, namely, Cashgate 1, Cashgate

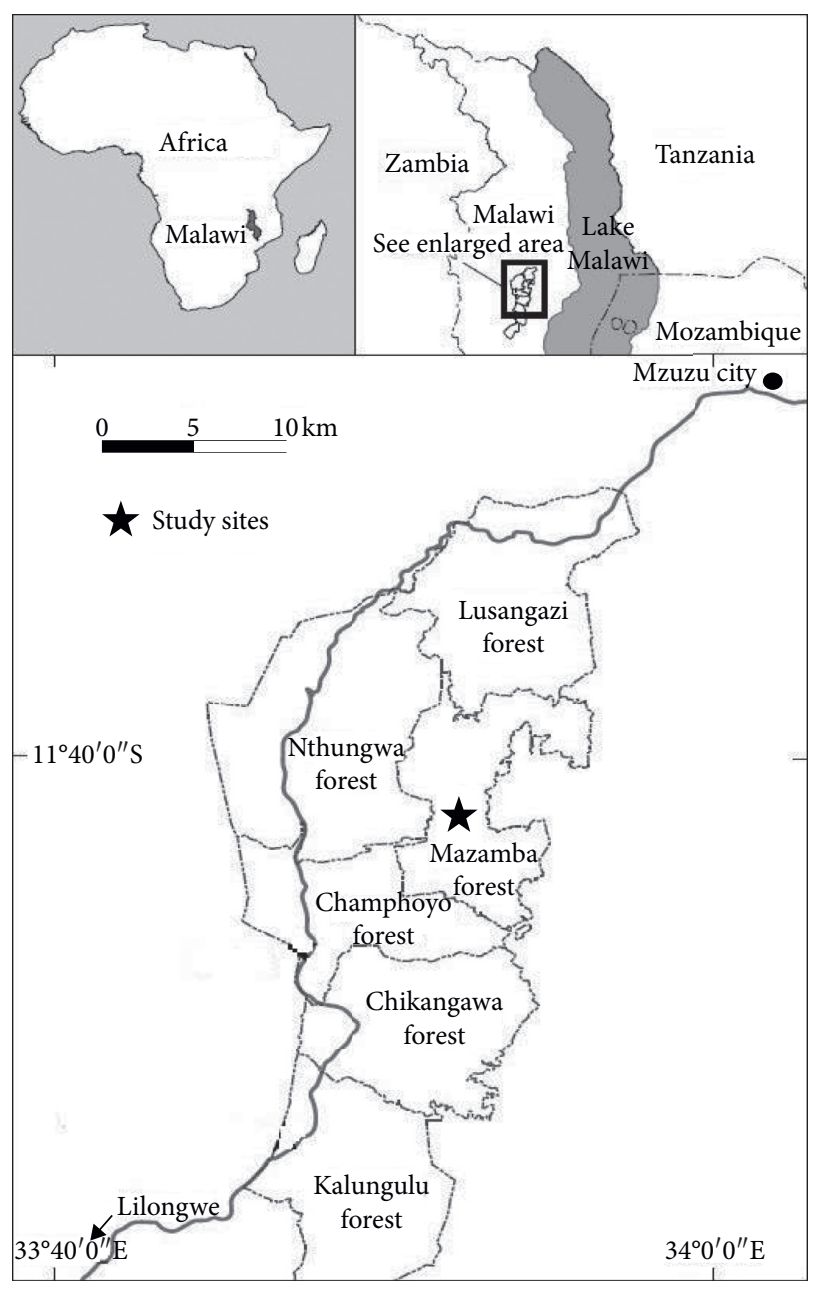

FIgURE 1: Map showing location of Mazamba forest station, adapted from [27].

2, Broken, and Bodobodo. These sites were distributed across Mazamba forest plantation sawing area.

2.2. Description of the Respondents. Due to the nature of work, the subject respondents involved in this study were only males. Their ages ranged from 19 to 49 years with the majority falling in the age class of 30-49 years. Only one respondent was below the age of 20 years. About $66 \%$ of the subjects had attended primary school education while the remaining percentage had at most attended secondary education. Their operational skills were variable. A few were experienced in timber harvesting and mobile sawmilling while the majority of them were unexperienced. Amec mobile mills were the most commonly used machines in sawmilling. Other timber producing (sawing) machines were woodmizers, chainsaws, and manually operated pitsaws.

2.3. Research Design and Sample Size. The study used a purposive sampling technique for saw millers and random sampling for forest community members. This involved selection of a sample from a population of workers involved 
in portable saw milling operations. The population comprised portable mill operators, assistants, log rollers, community members, and key informants. A sample size of 45 workers was drawn from a population of 130 workers. The selection of a sample size was largely based on experience and willingness to participate in the study. Workers with less than one-year experience were excluded in the study as they did not comprehensively possess institutional memory of wood processing accident activities. Nevertheless, this sample size was adequate to satisfy statistical requirements based on the central limit theory [28]. Machines involved were woodmizers, Amec, chainsaws, and pitsaws. A woodmizer uses a bandsaw to cut logs while an Amec cuts by using a circular saw blade. Both machines are powered by diesel engines. Chainsaws are motor-manual machines that are used to rip saw the logs while pitsaw blades are manually operated by two operators to do the same job.

2.4. Data Collection Methods and Variables. Data collection was done using a structured questionnaire administered through personal interviews. The questionnaire was designed to obtain information on the following key variables: main causes of accidents; severity of injuries; and appropriate mitigation measures of accidents. Pretesting of questionnaire was done prior to commencement of the exercise to ensure adaptability, relevance, and applicability of methods, questions, time, and approach in the study area.

2.5. Data Analysis. Data were organised and analysed using Statistical Package for the Social Sciences (SPSS) Version 16.0 for Windows. Percentage relative frequencies of respondents were determined. Chi-square tests were used to determine statistically significant $(P<0.050)$ differences among response frequencies in relation to independent variables in the study. Principal component analyses (PCA) on a nominal data scale were used to extract main components on causes and mitigation measures of accidents at eigenvalue $=1$.

\section{Results}

3.1. Main Causes of Accidents in Portable Saw Mills. The following causes of accidents were analysed: (1) inappropriate machine setup, (2) inadequate skills to operate the machine, (3) harsh weather conditions, (4) poor position of the sawmill operator, (5) drug consumption, (6) fatigue, and (7) weak supporting poles and ropes. The chi-square test (Table 1$)$ showed that there were highly significant $\left(\chi^{2}(6\right.$, $N=5)=25.78, P<0.001)$ differences on frequency distribution of responses to the causes of accidents in portable saw mills. Some $37.8 \%$ of the respondents indicated that inappropriate machine setup was the main cause of accidents. About eighteen percent of the responses indicated that inadequate operational skills were the main cause of accidents. At least $4.4 \%$ of the respondents indicated that accidents were mainly caused by fatigue and weak supporting poles to the machines. Results of the PCA showed that inappropriate machine setup, inadequate skills to operate machines, harsh weather conditions, and poor position of the sawmill operator had an eigenvalue $>1$, accounting for about $71.7 \%$ of cumulative variance. Inappropriate machine setup alone contributed about $20.3 \%$ of the total variance.

3.2. Level of Accidents in Portable Sawmills. Near-miss, minor, major, and fatal constituted the levels of accidents. The chi-square test on frequency distribution of responses on accident level showed that differences were highly significant, $\chi^{2}(3, N=45)=22.53, P<0.001$, in portable sawmills (Table 2). Respondents (55.6\%) indicated that nearmiss was the most frequently encountered accident. Twenty percent of the respondents indicated that they were involved in or witnessed minor accidents. At least $8.9 \%$ of the respondents reported to have witnessed fatal accidents in portable sawmills.

3.3. Preventive Measures of Portable Sawmill Accidents. The following variables were analysed for candidacy to preventive measures for accidents (Table 3): (1) using personal protective gear, (2) need for special training, (3) using ergonomically designed chainsaws, and (4) concentration while working. A chi-square test of independence showed that differences among these variables were highly significant $\chi^{2}(3, N=45)=134.02, P<0.001$. The use of personal protective gear accounted for $31.1 \%$ of the responses on accident prevention. Need for special training of workers to mitigate portable sawmill accidents had the highest $(57.8 \%)$ number of respondents. About $2 \%$ of the respondents indicated that accidents could be prevented by "concentrating" while working. A principal component analysis revealed that use of personal protective gear and provision of special training were the overarching variables (eigenvalue $>1$ ) for accident prevention among forest workers.

\section{Discussion}

4.1. Main Causes of Accidents. The highly significant $(P<0.001)$ differences of the main causes of accidents (Table 1) are related to personal and environmental factors. Personal factors entail the ability of workers to be able to appropriately execute tasks with minimal accident risks [29], while environmental factors relate to conditions in which the work is taking place. Thus, accidents were mainly caused by the inability to appropriately set up or operate machines and harsh weather conditions (Eigenvalue $>1$ ). Poorly setup machines yield unexpected motions and vibrations which are reason enough to cause occupational accidents. The cause for poor machine setup is partly attributed to difficult terrain (slope, ground roughness, and ground condition) in forest environments, poor technical condition of the machines (unbalanced telescopic leg lengths), and poor ground levelling techniques [30]. Furthermore, the influence of drug and/or alcohol consumption was also common among forest workers at Mazamba. Some workers believed that Cannabis sativa locally known as chamba smoking and/or alcohol consumption enhanced their productivity. On the contrary, literature [31-34] has discounted any assertions of improved 
TABLE 1: Response frequencies and variance account on causes of accidents.

\begin{tabular}{|c|c|c|c|c|c|c|}
\hline \multirow{2}{*}{$\begin{array}{l}\text { Causes of } \\
\text { accidents }\end{array}$} & \multirow{2}{*}{$\begin{array}{l}\text { No. of respondents } \\
\qquad(N=45)\end{array}$} & \multirow{2}{*}{$\begin{array}{l}\text { Relative frequency of } \\
\text { respondents }(\%)\end{array}$} & \multicolumn{3}{|c|}{ Initial eigenvalues } & \multirow{2}{*}{ Extracted component } \\
\hline & & & Total \% & $\%$ of variance & Cumulative \% & \\
\hline 1 & 17 & 37.8 & 1.423 & 20.327 & 20.327 & $*$ \\
\hline 2 & 8 & 17.8 & 1.307 & 18.675 & 39.002 & $*$ \\
\hline 3 & 7 & 15.6 & 1.178 & 16.831 & 55.833 & * \\
\hline 4 & 6 & 13.3 & 1.110 & 15.859 & 71.692 & $*$ \\
\hline 5 & 3 & 6.7 & 0.814 & 11.626 & 83.318 & \\
\hline 6 & 2 & 4.4 & 0.735 & 10.497 & 93.816 & \\
\hline 7 & 2 & 4.4 & 0.433 & 6.184 & 100.000 & \\
\hline$\chi^{2}$ & & 25.78 & & & & \\
\hline df & & 6 & & & & \\
\hline$P$ & & $<0.001$ & & & & \\
\hline
\end{tabular}

${ }^{*}$ Denotes extracted factors with eigenvalue $>1$.

TABLE 2: Responses on level of accidents encountered or witnessed.

\begin{tabular}{lcc}
\hline $\begin{array}{l}\text { Level of } \\
\text { accident }\end{array}$ & No. of respondents $(N=45)$ & Relative frequency (\%) \\
\hline Near-miss & 25 & 55.6 \\
Minor & 9 & 20.0 \\
Major & 7 & 15.6 \\
Fatal & 4 & 8.9 \\
\hline$\chi^{2}$ & & 22.53 \\
df & & 3 \\
$P$ & $<0.001$ \\
\hline
\end{tabular}

worker productivity. Instead, the substances abuse is said to slow down body coordination and mental ability, hence failure to set up and operate machines. The personal inefficiencies arise because most workers in Mazamba lack professional knowledge and training prior to timber harvesting and processing engagements. Similar studies on occupational safety [35-39] have acknowledged that personal factors are main causes of accidents.

Harsh weather was considered as an important environmental condition with regard to occupational safety for most workers. Exposure to precipitation while working induced slipperiness and visibility imprecision of objects. These were potential precursors to accident occurrences in the area. On the other hand, extreme temperatures created worker discomfort in the forest environment. Gnoni and Saleh [40] concur that unsafe conditions fail to meaningfully harness the safety value at workplace.

4.2. Levels of Accidents Incurred during Sawmilling. Accidents may exist as near-misses, minor, major and, in very extreme cases, fatalities. The ratio of near-miss:minor: major:fatal accidents is approximately 6:2:2:1 in Mazamba (Table 2). This implies that there are threefold near-misses in every minor or major accident with a probability of one fatal accident in timber processing operations. Although the trend on level of accidents mirrors a typical accident pyramid $[5,40]$, the frequency rate in Mazamba is generally higher. Near-misses, interpreted as close-to-accident events, were more frequent for the unsafe acts and conditions that existed in a workplace. For instance, drug abuse and incorrect lifting of logs were common unsafe acts observed, while noise levels and climatic factors were far below the specified threshold limits for worker exposure in Mazamba. In fact, most of the near-miss incidents go unnoticed by the workers.

Near-misses have far reaching consequences in as far as safety management is concerned [41]. It is cheaper to manage near-misses than higher-order accidents. Hence, a reduction of near-misses would simultaneously yield into a reduction of higher-order accidents for workers in the timber processing sector.

Meanwhile, the timber processing sector lacks comprehensive occupational accident analyses to enable accurate estimation of frequency and severity of accidents at workplace. Partly, this is attributed to practicing of temporal employment arrangements which do not provide amenable occupational social protection mechanisms [42]. Under temporal employment engagements, workers do not prioritise monitoring and evaluation (M\&E) of accident occurrences at workplace. Inadequate $M \& E$ is retrogressive to development of future occupational safety and health interventions in line with the Occupational Safety, Health and Welfare Act [43]. Garland [20] reported similar findings in Zambia where occupational safety progress became almost impossible in forest operations.

While inadequate $M \& E$ appears to be a global concern on frequency and severity of accidents at workplace, accident rates are generally lower in developed countries such as Finland, Sweden, and Chile [44]. Observations revealed that small-scale wood processing mills, like those at Mazamba, are more prone to accident occurrence. There is need to reduce manual handling, provide and enforce use of protective equipment, and use ergonomically designed machines.

4.3. Mitigation Measures of Accidents. Portable sawmill accidents could be prevented by using ergonomically designed machines, concentration while working, using personal protective equipment (PPE), and engaging in specialised training (Table 3). The use of ergonomically designed machines could enhance a positive human-machine interaction through improvement of safety, comfort, and performance. Most machine moving parts including saws run unguarded. 
TABLE 3: Frequency and variance accounted for by different preventive measures of accidents.

\begin{tabular}{|c|c|c|c|c|c|c|}
\hline \multirow{2}{*}{$\begin{array}{l}\text { Preventive } \\
\text { measures }\end{array}$} & \multirow{2}{*}{$\begin{array}{c}\text { No. of respondents } \\
\quad(N=45)\end{array}$} & \multirow{2}{*}{$\begin{array}{l}\text { Relative frequency } \\
\text { of respondents (\%) }\end{array}$} & \multicolumn{3}{|c|}{ Initial eigenvalues } & \multirow{2}{*}{$\begin{array}{c}\text { Extracted } \\
\text { component }\end{array}$} \\
\hline & & & Total \% & $\%$ of variance & Cumulative \% & \\
\hline 1 & 26 & 57.8 & 1.703 & 42.567 & 42.567 & $*$ \\
\hline 2 & 14 & 31.1 & 1.288 & 32.205 & 74.772 & $*$ \\
\hline 3 & 4 & 8.9 & 0.970 & 24.256 & 99.026 & \\
\hline 4 & 1 & 2.2 & 0.039 & 0.972 & 100.0 & \\
\hline$\chi^{2}$ & & 34.02 & & & & \\
\hline $\mathrm{df}$ & & 3 & & & & \\
\hline$P$ & & $<0.001$ & & & & \\
\hline
\end{tabular}

${ }^{*}$ Extracted factors with eigenvalue $>1$.

This is a high degree of safety hazard exposure of workers. According to Aneziris et al. [45], exposed machine moving parts are responsible for most of the accidents in sawmills. It is suggested that careful movements of workers and machine component guarding should be exercised as far as possible in the workplace in order to limit exposure to hazards.

Secondly, concentration while working is integral to prevention of risky incidences. It was highlighted that some workers lose their concentration at work because of participating in group or mobile phone conversations while working. This confirms the observation that workers did not have predetermined rest (break) times on which they could share social news and updates. It is important that workers have enough rest times and avoid fatigue and exhaustion to avoid loss of concentration according to Tsioras et al. $[22,46]$.

Personal protective equipment (PPE) and specialised training are probably the most important (Eigenvalue $>1$ ) accident mitigation measures. PPE helps to protect the worker at the "individual level." It also helps to reduce exposure duration of workers to potentially hazardous environments [47]. Most forest workers were observed to be using ordinary clothing rather than the specified protective gears. Part of the reason to this outcome was that some workers were not supplied with PPE by their employers. For those that had the protective gear, they argued that most protective equipment was either not user friendly or heavy to carry. Furthermore, unwillingness to use PPE was amplified by peer pressure among workers themselves. These arguments concur with the findings of [48] which indicated that effective use of personal protectors is largely governed by perceptions, misfit of PPE, and enforcement initiatives. When the use of PPE is not enforced, workers tend to ignore its use, and this makes their employers neglect provision of the gear. According to Klen [49], it may be important to further investigate perceptions of workers on their physical and psychological safety value in the workplace. However, Hull et al. [50], European Agency for Safety and Health at Work [7], and Laschi et al. [46] support evidence for safety value in use of PPE. Perhaps, introduction of local occupational safety and health structures in Mazamba could help to enforce safety issues.
The importance of worker training is overarching to mitigation of workplace accidents as demonstrated by the frequency of responses (37.8\%) in Table 3. It was established that most of the workers enter into the timber processing profession without prior training. Learning is accumulated on-site through observation of their colleagues. This can be detrimental to personal and other people's safety as such workers lack basic occupational safety and health and ergonomic knowledge and skills. It was further established that workers lack formal training because of their educational backgrounds as the majority of whom are primary school leavers or secondary school dropouts. Hence, they are unable to effectively read instructions and engage in formal training.

Lastly, there are no customized training service programmes provided for frontline forest machine operators in Viphya. As such, customized training could be ideal for this group in order to mitigate accidents in Mazamba. Several researchers [51, 52] and Ghaffariyan [39] attest to the fact that trained workers are finitely less risky in being involved or causing accidents in the workplace.

\section{Conclusions and Recommendations}

Accidents in portable sawmills mostly arise from unsafe acts and conditions in the workplace. Machine operators lacked knowledge and skills to effectively set up and operate their machines. Drug and alcohol abuse were responsible for most forest occupational accidents with the majority of workers frequently encountering near-misses. Therefore, operator training that focuses on the removal of near-misses would translate in the reduction of higher-level accidents such as major accidents and fatalities. Accidents can further be mitigated by use of personal protectors and training prior to engaging in the profession.

It is recommended that accident analyses are comprehensively structured in future occupational safety and health interventions in timber harvesting and wood processing sectors. Future studies should unearth statistics on the types, magnitude, and severity of accidents in the forest workplace. It is important that local safety structures be instituted to enable near-miss management, safety training, ergonomics, and occupational safety and health enforcement. While participation of small-scale sawmilling activities is useful in 
Viphya, there is need to ensure adherence to best operating practices at all time in order to prevent occupational accidents.

\section{Data Availability}

This study was developed from newly collected and analysed data in partial fulfilment of the requirements of BSc degree qualification of and by Mr. Jameson T. T. Mzungu at Mzuzu University, Malawi. The data sets can be found at Mzuzu University in the Department of Forestry and Environmental Management.

\section{Conflicts of Interest}

The authors declare that no conflicts of interest exist in the funding and publication of this article.

\section{Acknowledgments}

The authors are grateful to the Department of Forestry and Environmental Management staff at Mzuzu University for their technical support in enabling operationalisation of this study. Thanks are also due to the Viphya Sawmillers Union and Mr. Stepples Nyandeni (Viphya Forester) for their assistance during data collection.

\section{References}

[1] N. Black, M. Dilworth, and N. Summers, "Occupational exposure to wood dust in the British woodworking industry in 1999/2000," The Annals of Occupational Hygiene, vol. 51, no. 3, pp. 249-260, 2007.

[2] A. Eng, A. T. Mannetje, J. Douwes et al., "The New Zealand workforce survey II: occupational risk factors for asthma," The Annals of Occupational Hygiene, vol. 54, no. 2, pp. 154-164, 2010.

[3] M. R. Mylek and J. Schirmer, "Beyond physical health and safety: supporting the wellbeing of workers employed in the forest industry," Forestry, vol. 88, no. 4, pp. 391-406, 2015.

[4] J. Suchomel, K. Belanova, M. Vičková, and A. Janečk, "Work accidents development in timber harvesting and yarding process," Logging and Processing in Central Europe, vol. 20-21, pp. 110-114, 2007.

[5] H. W. Heinrich, Industrial Accident Prevention: A Scientific Approach, McGraw-Hill, New York, NY, USA, 4th edition, 1959.

[6] M. V. P. Aaltonen, E. Uusi-Rauva, J. Saari, M. Antti-Poika, T. Räsänen, and K. Vinni, "The accident consequence tree method and its application by real-time data collection in the Finnish furniture industry," Safety Science, vol. 23, no. 1, pp. 11-26, 1996.

[7] European Agency for Safety and Health at Work, Preventing Accidents at Work, Office for Official Publications of the European Communities, European Agency for Safety and Health at Work, Luxembourg, France, 2001.

[8] M. Abbas, "Trend of occupational injuries/diseases in Pakistan: index value analysis of injured employed persons from 2001-02 to 2012-13," Safety and Health at Work, vol. 6, no. 3, pp. 218-226, 2015.

[9] K. Ojanen, Forestry Operations and OSH Issues: From the Past to the Present, Finnish Institute of Occupational Health, Helsinki, Finland, 2006.
[10] I. Potočnik, T. Pentek, and A. Poje, "Severity analysis of accidents in forest operations," Croatian Journal of Forest Engineering, vol. 30, pp. 171-184, 2009.

[11] P. Albizu-Urionabarrenetxea, E. Tolosana-Esteban, and E. Roman-Jordan, "Safety and health in forest harvesting operations. diagnosis and preventive actions. a review," Forest Systems, vol. 22, no. 3, pp. 392-400, 2013.

[12] I. Potočnik and A. Poje, "Forestry ergonomics and occupational safety in high ranking scientific journals from 2005-2016," Croatian Journal of Forest Engineering, vol. 38, no. 2, pp. 291-310, 2017.

[13] K. Ahola, S. Toppinen-Tanner, P. Huuhtanen, A. Koskinen, and A. Väänänen, "Occupational burnout and chronic work disability: an eight-year cohort study on pensioning among finnish forest industry workers," Journal of Affective Disorders, vol. 115, no. 1-2, pp. 150-159, 2009.

[14] W. H. Parry, F. Martorano, and E. K Cotton, "Management of life-threatening asthma with intravenous isoproterenol infusions," American Journal of Diseases of Children (1960), vol. 130, no. 1, 39 pages, 1976.

[15] T. A. Bentley, R. J. Parker, and L. Ashby, "Understanding felling safety in the New Zealand forest industry," Applied Ergonomics, vol. 36, no. 2, pp. 165-175, 2005.

[16] D. Tappin, M. Edwin, and D. Moore, "Sawmill accident register records: main findings of a survey from 37 mills," Centre for Human Factors and Ergonomics Report, vol. 4, no. 5, pp. 1-6, 2003.

[17] P. Balsari, P. Cielo, and R. Zanuttini, "Risks for the health of workers in plywood manufacturing: a case in Italy," IJFEInternational Journal of Finance \& Economics, vol. 10, pp. 37-53, 1999.

[18] International Labour Organisation, ILO Thesaurus, International Labour Organisation, Geneva, Switzerland, Ihttp:// www.ilo.org/public/libdoc/ILO-Thesaurus, 2005.

[19] D. A. Silayo, S. S. Kiparu, E. W. Mauya, and D. T. K. Shemwetta, "Working conditions and productivity under private and public logging companies in Tanzania," Croatian Journal of Forest Engineering, vol. 31, pp. 65-74, 2010.

[20] J. J. Garland, Accident Reporting and Analysis in Forestry: Guidance on Increasing the Safety of Forest Work, Forestry Working Paper No. 2, FAO, Rome, Italy, 2018.

[21] S. R. Bello and Y. Mijinyawa, "Assessment of injuries in small scale sawmill industry of south western Nigeria," CIGR Journal, vol. 12, pp. 151-157, 2010.

[22] P. A. Tsioras, C. Rottensteiner, and K. Stampfer, "Analysis of accidents during cable yarding operations in Austria 19982008," Crojfe Journal of Forest Engineering, vol. 32, pp. 549$560,2011$.

[23] P. Blombäck, P. Poschen, and M. Lövgren, Employment Trends and Prospects in the European Forest Sector: European Forest Sector Outlook Study (EFSOS), United Nations, Geneva, Switzerland, 2003.

[24] G. Papadopoulos, P. Georgiadou, C. Papazoglou, and K. Michaliou, "Occupational and public health and safety in a changing work environment: an integrated approach for risk assessment and prevention," Safety Science, vol. 48, no. 8, pp. 943-949, 2010.

[25] G. Neely and E. Wilhelmson, "Self-reported incidents, accidents, and use of protective gear among small-scale forestry workers in Sweden," Safety Science, vol. 44, no. 8, pp. 723-732, 2006. 
[26] K. Y. Rhee, Y. S. Kim, and Y. H. Cho, "The type of payment and working conditions," Safety and Health at Work, vol. 6, no. 4, pp. 289-294, 2015.

[27] E. Ngulube, M. Brink, and P. W. Chirwa, "Productivity and cost analysis of semi-mechanised and mechanised systems on the viphya forest plantations in malawi," Southern Forests: A Journal of Forest Science, vol. 76, no. 4, pp. 195-200, 2014.

[28] I. Berkes and E. Csáki, "A universal result in almost sure central limit theory," Stochastic Processes and Their Applications, vol. 94, no. 1, pp. 105-134, 2001.

[29] V. Hampl, Development of Criteria for Control of Woodworking Operation, OHSA Publications, Washington, DC, USA, 1982.

[30] J. Kays, Developing a Custom Portable Sawmill Enterprise, Natural Resource, Agriculture, and Engineering Service, NRAES), New York, NY, USA, 2007.

[31] G. Taylor, K. Easter, and R. Hegney, Enhancing Occupational Safety and Health, Elsevier Butterworth/Heinemann, Oxford, England, UK, 2004.

[32] Alcohol Advisory Council of New Zealand, Accident Compensation Corporation: Alcohol and Other Drugs in the Workplace, New Zealand Drug Foundation, Wellington, New Zealand, 2008.

[33] M. R. Frone and A. L. Brown, "Workplace substance-use norms as predictors of employee substance use and impairment: a survey of U.S. workers*," Journal of Studies on Alcohol and Drugs, vol. 71, no. 4, pp. 526-534, 2010.

[34] R. Kenley, Safety Impacts of Alcohol and Other Drugs in Construction, SBEnrc Industry Report, University of Technology, Queensland, Brisbane, 2012.

[35] A. Thelin, "Fatal accidents in swedish farming and forestry, 1988-1997," Safety Science, vol. 40, pp. 501-517, 2002.

[36] J. Klun and M. Medved, "Fatal accidents in forestry in some European countries," Croatian Journal of Forest Engineering, vol. 28, pp. 55-62, 2007.

[37] C. D. B. Burt, N. Chmiel, and P. Hayes, "Implications of turnover and trust for safety attitudes and behaviour in work teams," Safety Science, vol. 47, pp. 1002-1006, 2008.

[38] K. Melemez, "Risk factor analysis of fatal forest harvesting accidents: a case study in Turkey," Safety Science, vol. 79, pp. 369-378, 2015.

[39] G. Mr, "Analysis of forestry work accidents in five Australian forest companies for the period 2004 to 2014," Journal of Forest Science, vol. 62, no. 12, pp. 545-552, 2016.

[40] M. G. Gnoni and J. H. Saleh, "Near-miss management systems and observability-in-depth: handling safety incidents and accident precursors in light of safety principles," Safety Science, vol. 91, pp. 154-167, 2016.

[41] S. P. Penkey and N. A. Siddiqui, "A review on accident pyramid and its empirical interpretation in oil and gas industry," IJSRP-International Journal of Scientific and Research Publications, vol. 5, pp. 1-2, 2015.

[42] C. Ackerknecht, "Work in the forestry sector: some issues for a changing workforce," Unasylva, vol. 234/235, no. 61, pp. 60-65, 2010.

[43] Government of Malawi, Occupational Safety, Health and Welfare Act, Lilongwe, Malawi, 1997.

[44] C. Ackerknecht, "Occupational safety indicators for forest operations, sawmilling and wood-based panels manufacture: an international benchmarking," Ciencia \& Trabajo, vol. 17, no. 53, pp. 89-98, 2015.

[45] O. N. Aneziris, I. A. Papazoglou, M. Konstandinidou et al., "Quantification of occupational risk owing to contact with moving parts of machines," Safety Science, vol. 51, no. 1, pp. 382-396, 2013.

[46] A. Laschi, E. Marchi, C. Foderi, and F. Neri, "Identifying causes, dynamics and consequences of work accidents in forest operations in an alpine context," Safety Science, vol. 89, pp. 28-35, 2016.

[47] J. Dul and B. Weerdmeester, Ergonomics for Beginners: A Quick Reference Guide, Taylor and Francis Group, London, UK, 2001.

[48] D. A. Lombardi, S. K. Verma, M. J. Brennan, and M. J. Perry, "Factors influencing worker use of personal protective eyewear," Accident Analysis \& Prevention, vol. 41, no. 4, pp. 755-762, 2009.

[49] T. Klen, "Personal protectors and working behaviour of loggers," Safety Science, vol. 25, no. 1-3, pp. 89-103, 1997.

[50] B. P. Hull, J. Leigh, T. R. Driscoll, and J. Mandryk, "Factors associated with occupational injury severity in the New South Wales underground coal mining industry," Safety Science, vol. 21, no. 3, pp. 191-204, 1996.

[51] S. Axelsson, "The mechanization of logging operations in Sweden and its effect on occupational safety and health," IJFEInternational Journal of Finance \& Economics, vol. 9, pp. 25-31, 1998.

[52] Health and S. Executive, Health and Safety in Sawmilling, Health and Safety Executive, London, UK, 2012. 